\section{Bsax SciencePrank Research, Organizadion \& Counseling \\ New Trends and Issues Proceedings on Humanities and Social Sciences}

Issue 2 (2017) 14-22

\title{
Streamline of the teaching methods for enhancing the student motivation at the University
}

Kristina Trskova ${ }^{a}$, University of Žilina, Univerzitná 1, 01026 Žilina, Slovakia

\section{Suggested Citation:}

Trskova, K. (2017). Streamline of the teaching methods for enhancing the student motivation at the University. New Trends and Issues Proceedings on Humanities and Social Sciences. [Online]. 02, pp 14-22. Available from: www.prosoc.eu

Selection and peer review under responsibility of Prof. Dr. Marilyn Campbell, Queensland University of Technology, Australia

${ }^{\circledR} 2016$ SciencePark Research, Organization \& Counseling. All rights reserved.

\begin{abstract}
Motivation of human resource is important not only in working area but also for students who are preparing themselves for the future career. This paper therefore focused on students' motivation and suggests the ways of developing the teaching methods in order to increase their motivation for improve their knowledge and skills. Methodological part of the paper presents the results of the questionnaire survey executed at the University of Žilina. The sample consists of 70 students of the first year of bachelor study program Management. The questionnaire is dedicated to: Factors which motivates the students to fulfil their tasks; the level of students' skills development before and after the completion of subject; students' awareness; and detection of weak moments during teaching which offer the opportunity for improvement. Based on survey, the paper reveals weaknesses in teaching and contains proposals and recommendations for streamlining the teaching to enhance students' motivation and their interest in development of their skills and knowledge. In the application part of this paper, there are suggested methods which are based on theoretical knowledge, questionnaire survey, and own observation and experiences (for example: Increasing students' awareness on their responsibilities, duties, conditions, evaluation criteria and education program).
\end{abstract}

Keywords: motivation; students; skills; survey; knowledge;

* ADDRESS FOR CORRESPONDENCE: Kristina Trskova, University of Žilina, Univerzitná 1, 01026 Žilina, Slovakia

E-mail address: kristina.trskova@fri.uniza.sk / Tel.: ++421-41-513-4020. 
Trskova, K. (2017). Streamline of the teaching methods for enhancing the student motivation at the University. New Trends and Issues Proceedings on Humanities and Social Sciences. [Online]. 02, pp 14-22 Available from: www.prosoc.eu

\section{Introduction}

Teachers are the key parts of a university. The attributes expected from a qualified teacher are various and include a suitable personality, good teaching skills, research competence, rich knowledge, good skills for classroom management and communication and professional dedication (Shu, 2005). Klingner and Vaughn (2002, p. 30) have concluded, the role of the inclusion teacher is complex and multifaceted and depends largely on the teachers' interpersonal and communication skills. Interpersonal and communication skills are essential for building good workplace relationships, friendly atmosphere of trust and openness and for good relationships with students, what is the basis of stimulating motivation of students and teachers themselves.

Motivation has been widely accepted by teachers and researchers as one of the key factors that can influence the rate and success of learning. Teaching method is a form, and the purpose of taking a teaching method is to stimulate the students' motivation in learning (Dornyei, 1998). The teacher is rather facilitator than director and helps students in any way that motivates them to learn. This results not only in an overall motivational climate which further facilitates learning but also in harmonious interpersonal relationships between the teacher and the students (Zhe, 1997). An effective teacher should first of all be willing to make efforts to understand the students. The more we know about our students, the easier our teaching will be (GU, 1996). Understanding the students is very difficult as each student is unique, has different needs, expectations and motivation as his classmates. All learners are likely to be influenced by their personal feelings about their teachers, and therefore, their perceptions of their teachers and of the interactions that occur between them and their teachers will undoubtedly affect their motivation to learn (Williams \& Burden, 1997).

\section{Motivating of Students}

Life would be marvelous for teachers if all students wanted to learn. According to Biggs, students can only be motivated to learn things that are important and meaningful to them. However, most students are demotivated by the emphasis placed on difficult and abstract declarative knowledge in school. Consequently, they tend to find learning in school uninteresting, or irrelevant to their daily life, which results in the lack of attention, passivity, and positive attitudes (Biggs, 1991). It is very important to explain students how can their acquired skills and knowledge be used in their lives in the best possible way and where they can encounter the helpfulness of these skills. For students it is needed to understand the importance of taught subject topics so they will be motivated.

Motivation is the internal process that initiates, maintains and guides external behavior, and has always been an important variable in education and learning (Slavin, 2003; Richards, Schmidt, Kendrick \& Youngkyu, 2003; Woolfolk, 2004). If students do not have motivation to educate themselves, they would not have the reason to go to university and so teachers would not have anybody for teaching. Gardner \& MacIntyre (1991) defined motivation as the learner's orientation with regard to the goal of learning; it is the impetus to create and sustain intentions and goal-seeking acts, it is important because it determines the extent of the learner's active involvements and attitudes towards learning; the social psychological perspective has defined motivation as a composite of intensity and orientation that correspond respectively to the effort expended and to the learner's goals; it refers to a combination of the learner's attitudes, aspiration and effort with respect to learn.

The motivating (as the process of influencing someone's motivation) represents a purposeful, permanent and thinking-relational process the intention of which consists in creating suitable conditions and using convenient motivational approaches, tools, events, and measurements in a way that the quality and value of the individual effort can be increased (Blašková \& Blaško, 2011). If there are created appropriate conditions, friendly surrounding and open atmosphere of trust for students 
and suitable motivation-based approaches, procedures and methods are used during teaching, the value of students' outputs increases.

Motivation refers to a combination of the learner's attitudes, desires, and willingness to expend effort in order to learn (Gardner \& Lambert, 1959; Keller \& Vallerand, 1983; Richards et al, 2003). If we adopt the right way to arouse their motivation and prompt them to learn, they would make great progress in learning and upgrade the level of study (Downs, 2001; Zhang \& Fu, 2008). It is important for the teacher to recognize the significance of motivation and make good use of it in teaching practice. It is this favorable attitude, combined with diligent effort that composes true motivation (Downs, 2001). From previous definitions we can get an idea about motivation strategies which can be defined as behavior, steps, stages, techniques, approaches, procedures used by teacher to motivate students in learning.

Teachers should create a safety atmosphere during lessons. This means to create open, harmonious, sincere atmosphere based on mutual trust and to encourage students to express their opinions, ideas, inspirations and feelings. To give them feeling that they themselves decide about their direction. When students feel the learning acquired in class is altering their lives, they are more likely to be intrinsically motivated (Wlodkowski, 1997, p. 31). Nunan lists, Allowing learners to bring their own knowledge and perspectives into the learning process as one of the most significant ways to increase students' motivation. This "prizing" of the student's feelings and opinions makes the classroom truly learner-centered (Rogers, 1980). Very strong motivational measures include a receiving motivational inspiration from other successful individuals. In this spirit, an example of positive motivational patterns can be received from people whose motivation is very high (Blašková et. al., 2015). Since the teachers are becoming an idol for their students that can affect them not only during study but also after it, teachers should take care and permanently develop their own internal motivation through self-education, skills development, creativity and so on. University teachers pass to the students not only knowledge about subject they teach, but they also profile students for future profession and they shape competencies necessary for their active personal life (Blašková \& Blaško, 2013).

Motivation is defined in different ways by different researchers, but they seem to agree that motivation is responsible for determining human behavior by energizing it and giving it direction. One of the most general and well-known distinctions in motivation theories is that of intrinsic versus extrinsic motivation (Wang, 2008). Extrinsic motivation has traditionally been seen as something that can undermine intrinsic motivation; several studies have confirmed that students will lose their natural intrinsic interest in an activity if they have to do it to meet some extrinsic requirement. However, research has shown that under certain circumstances - if they are sufficiently selfdetermined and internalized - extrinsic rewards can be combined with or can even lead to intrinsic motivation (Dornyei, 1998). Extrinsic motivation can be used to reinforce intrinsic motivation; to some extent, extrinsic motivation cannot remain for a long time, which needs constant reinforcement and long-term effects are from intrinsic motivation (Wang \& Zhao, 2005). Intrinsic motivation deals with behavior performed for its own sake, in order to experience pleasure and satisfaction such as the joy of doing a particular activity or satisfying one's curiosity (Wang, 2008).

\subsection{Feedback}

It is generally maintained that from a motivational point of view informational feedback should be dominant since it enables students to understand where they are in relation to achieving goals and what they need to do to continue or improve their progress (Jones and Jones, 1995, adapted from Fu Rui-ping 2008). Behaviorist psychologists first perceived the colossal influence of feedback exerted on 
motivation. Weinstein (1989) once explicitly pointed out that the form and amount that were supplied by the teacher had a direct influence on the learner's study motivation, self-awareness and sense of achievement in study, which, furthermore, influenced the students' study effect.

\section{Survey}

The questionnaire survey was conducted at the University of Žilina, Slovakia in December 2015. The target group was represented by students of first year of bachelor degree (Faculty of Management and Informatics, Department of Management) which completed the subject Managerial Presentation Skills.

Aim of the subject Managerial Presentation Skills is to increase the level of students' presentation skills, learn them perceive and utilize verbal and nonverbal expression, prepare and interpret the results, enhance their presentation technically and graphically, use multimedia components, handle critical moments during the presentation, and so on.

The questionnaire included questions focused on students' awareness of this subject successful completion conditions, teaching plan, evaluation criteria, and requirements for the semester work. Another parts of the questionnaire were devoted to the level of motivation to various factors (loss of points, possibility to gain an above average valuation, praise from schoolmates, praise from teacher, collective punishment, setting deadlines, obligation to public presentation, obtain of new skills and

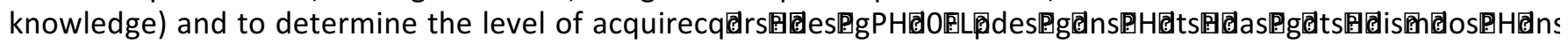


Another question was open - we were asking students for the strongest and the weakest moment of the exercises where they learned to practice presentations skills. The possibility to acquire new skills in the form of professional managerial manners and presentation was shown as the strongest moment of the exercises. . All students could test these skills on the last special group presentation which took place on the common lecture in front of all students of the academic year and several teachers. Students were very interested in this kind of testing and, because they have never met with such type of presenting, it was very motivational for them. The fact that acquisition of new skills is the lessons strongest moment for students indicates that during teaching the teacher should focus on using methods which will contribute to the development of students' skills in the area. It is also very necessary to keep in mind the feedback as this is the only way to verify the students' actual acquisition of mentioned skills. The best feedback is practical demonstration of the gained skills and knowledge usage, but not in stressful situations (which the final exams might be), but during friendly and relaxed atmosphere and motivational climate. To put students into stressful situation has demotivational effects causing nervousness and results in a reduction of their ability (and willingness) to make full use of newly acquired skills. In the survey students expressed the opinion that the weakest moments of the exercises were stage fright and stress which caused the reduction of their ability to present and to concentrate on minimizing mistakes. According to these facts teacher should use adequate effort to reduce negative stress to a minimum (respectively to transform negative stress into eustress) what can be provided with help of motivational approach.

As one of the most effective teaching motivational tools have proved:

- Students praise for a well done job.

- The opportunity to earn bonus valuation beyond the standard scale, if the student submits an extraordinary performance.

- To give the space for students to express their opinions, ideas, inspiration (what supports their creativity) and to include these into teaching plan so the students have the feeling that they are beneficial to the subject and that they participate on its creation.

It is needed to think about another strong motivational tool for students which are also exemplary samples of the use of their new skills and knowledge in practice and when they already see what benefits it will bring for them if they will intensely devote to their own development in this area. If they consider these skills as useless or redundant in practice, they would lose the motivation to gain and develop these skills.

The fact that during twelve lessons the level of students' presentation skills increased by $34 \%$ in average should be the stimulus to put appropriate emphasis not only on the transfer of knowledge, findings and information to students but also on the acquisition of the skills. Before completing the subject Managerial Presentation Skills students evaluated their average presentation skills level to $40.6 \%$ (what represents notable below-average level) and after completion of the subject it was evaluated to $74.6 \%$ in average (where $100 \%$ is an expert in this field). Despite this high number it is necessary to put even more emphasis on developing students' skills as they said that it is the very powerful motivational tool for them and they are interested in developing their skills even in a greater extent. In the next part of survey, we focused on exploring the relation between importance of acquiring the presentation skills perceived by students and the level of the actually acquired skills. This dependency was examined through chi-square test. 
Table 1. Frequency of Characters Between Importance of Acquired Presentation Skills and Level of Acquired Presentation Skills After Passing Lesson Managerial Presentation Skills

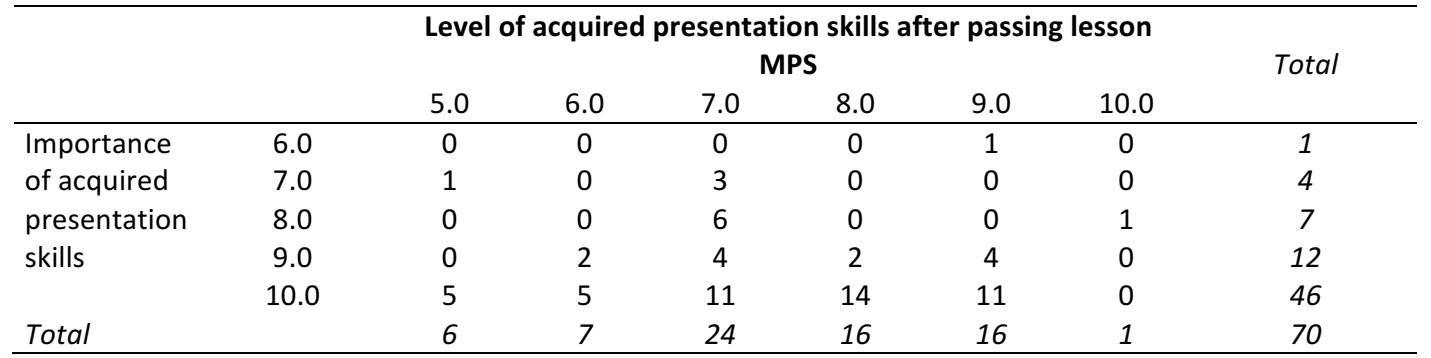

Table 2. Chi Square Test for Importance of Acquired Presentation Skills and Level of Acquired Presentation Skills after Passing Lesson Managerial Presentation Skills

\begin{tabular}{lccc}
\hline & Value & df & Asymp. Sig. (2-sided) \\
\hline Pearson Chi-Square & $\mathbf{3 2 . 9 6 5} \mathrm{a}_{\text {a }}$ & 20 & .034 \\
Likelihood Ratio & 33.256 & 20 & .032 \\
N of Valid Cases & 70 & & \\
\hline
\end{tabular}

Tabulated chi-square value at degrees of freedom 20 and significance level $0.05 \%$ is 31.4 , i.e. lower than calculated value (Table 2). This calculation proves that the relationship between perceived importance of acquiring presentation skills and the achieved level of actually acquired presentation skills after completing the Managerial Presentation Skills is confirmed. Based on this fact we can conclude that it is very important to follow the students' expectations which they consider as important for their further development (in this case it is the importance of acquiring the presentation skills) and to fulfill them to students' biggest satisfaction. The importance was measured on a scale from 1 to 10 where 1 means absolutely unimportant and 10 means absolutely important (essential). Acquired presentation skills were measured also on the scale from 1 to 10, where 1 means no presentation skills acquired and 10 means presentation skills acquired on expert level. From Table 1 it can be seen that students consider the presentation skills acquisition as very important because none of them marked a value lower than 6 (what represents 60\%). According to this the students' aim is not only to gain credits but they are interested also in the function of the subject.

Table 3. Frequency of Characters Between Level of Awareness of Valuation Parameters and Study Group

\begin{tabular}{lllllllllllll}
\hline & & \multicolumn{1}{c}{ Level of awareness } \\
& & 1 & 2 & 3 & 4 & 5 & 6 & 7 & 8 & 9 & 10 & Total \\
\hline Group & Group 1 & 0 & 0 & 0 & 0 & 0 & 0 & 1 & 1 & 9 & 7 & 18 \\
& Group 2 & 0 & 0 & 0 & 0 & 0 & 0 & 0 & 0 & 4 & 10 & 14 \\
& Group 3 & 1 & 0 & 0 & 2 & 0 & 4 & 1 & 3 & 0 & 2 & 13 \\
& Group 4 & 0 & 0 & 0 & 0 & 0 & 0 & 2 & 4 & 6 & 3 & 15 \\
& Group 5 & 0 & 0 & 2 & 0 & 1 & 0 & 0 & 1 & 2 & 4 & 10 \\
\hline
\end{tabular}


Trskova, K. (2017). Streamline of the teaching methods for enhancing the student motivation at the University. New Trends and Issues Proceedings on Humanities and Social Sciences. [Online]. 02, pp 14-22 Available from: www.prosoc.eu

Table 4. Chi-Square Test for Level of Awareness of Valuation Parameters and Study Group

\begin{tabular}{lccc}
\hline & Value & df & Asymp. Sig. (2-sided) \\
\hline Pearson Chi-Square & $\mathbf{8 6 . 3 7 2}$ & 56 & .006 \\
Likelihood Ratio & 71.230 & 56 & .083 \\
N of Valid Cases & 70 & & \\
\hline
\end{tabular}

The next section of the survey is dedicated to explore the relation between composition of study groups and awareness of the evaluation criteria. This focus was chosen because students were divided into five study groups, while study group 1 and 2 were taught by a different teacher than study groups 3,4 and 5. Each of these teachers used different teaching style and approach. Awareness of evaluation criteria has been chosen because for students' motivation it is essential to know what evaluation criteria are chosen for them and how can they achieve these criteria. If the student is not sure what will he/she be evaluated for and how is it possible to achieve particular evaluation criteria, it leads to reduction of his/her motivation level and to loss of his/her interest in acquiring or developing new skills.

The relationship between study groups and consciousness of the evaluation criteria was also calculated using the chi-square test. Tabulated chi-square values at degrees of freedom 56 and significance level $0.05 \%$ is 74.46 , which is lower than the calculated value (Table 4), what indicates confirmation of the dependence between these two factors. From Table 3 we can deduce that at study groups 3, 4 and 5 was the awareness level lower, resp. some evaluation criteria were not sufficiently understood or students did not know the way of achieving the criteria to $100 \%$. Based on this relation we can conclude that it is needed for students to be properly informed not only about evaluation criteria and parameters but also about the possibilities and ways how these criteria cab be fulfilled (reached), because it has been shown that in group with weaker awareness was also lower level of the acquired presentation skills what is connected also with lower students' motivation level.

\section{Conclusion}

Based on previous theoretical results we can argue that highly-motivated university teacher who has high-quality skills, knowledge, substantial experience and diverse creativity, who is opened to new ideas and inspirations, and who has the ability and lust for further develop his or her knowledge and skills, is the 'basic building unit' of high-quality university. If right these teachers with highly-qualified human potential will work for the university than the university itself is on the best way to become a prestigious, popular and influential university not only domestically, but also on the foreign market.

If a university teacher is not motivated in his or her inner side (he/she does not feel a high level of his/her own inner motivation), he or she cannot apply sufficient motivational approach to students because he or she does not trust this him/herself. As it was confirmed by the survey, students with continuous motivational approach throughout entire semester were able to acquire new skills and knowledge which the subject was offering to them. Even students to which was selected an approach with motivational accent in all the learning processes (from initial familiarization with classmates, teachers and subject; reporting information about the subject; to the final assessment of their success in the subject and feedback) largely use their newly acquired skills and knowledge also in other subjects, from the beginning intentionally, consciously being aware of their use and effectiveness, and after some time and frequent correct using of these skills they will learn to use them automatically intuitively. Students, who this motivational approach was not applied to lost these skills due time or the skills were suppressed.

Teacher's motivational approach left in students' minds positive impressions and memories which they have experienced while acquiring new skills. These positive impressions and memories are motivational not only to the active use of skills but also to their further development. Also when using these skills students feel much smaller stress (some of them even none). On the contrary, poorly 
Trskova, K. (2017). Streamline of the teaching methods for enhancing the student motivation at the University. New Trends and Issues Proceedings on Humanities and Social Sciences. [Online]. 02, pp 14-22 Available from: www.prosococ 
Trskova, K. (2017). Streamline of the teaching methods for enhancing the student motivation at the University. New Trends and Issues Proceedings on Humanities and Social Sciences. [Online]. 02, pp 14-22 Available from: www.prosoc.eu

Dornyei, Z. (1998). Motivation in second and foreign language learning. language teaching. UK: Cambridge University Press, 117-135. doi:10.1017/S026144480001315X.

Downs, M. (2001). A question of motivation. ELI Teaching: A Journal of Theory and Practice, 30-35.

Fu Rui-ping. (2008). Case study of teachers' mmotivational comments. Sino-US English Teaching,5(2, Serial 50).

Gardner \& Lambert. (1959). Teaching and researching motivation. Beijing: Foreign Language. Teaching and Researching Press.

Gardner, R. C. \& Maclntyre, P. D.. (1991). An instrumental motivation in language study: Who says it isn't effective. Second Language Acquisition, 13(1), 57-72.

Gu P. Y. (1996). Exploring ways to understand learning and improve teaching. TESL Reporter, 34-40.

Keller \& Vallerand. (1983). Motivation: Reopening the research agenda. Language Learning.

Klingner, J. K. \& Vaughn, S. (2002). The changing roles and responsibilities of an LD specialist. Learning Disability Quarterly, 25(1).

Nunan. (1999). Second language teaching and learning. Boston: Heinle \& Heinle Publishers.

Richards, J. C., Schmidt, R., Kendrick, H. \& Youngkyu, K. (2003). Longman dictionary of language teaching \& applied linguistics. Beijing: Foreign Language Teaching and Research Press.

Rogers, C. (1980). A way of being: The process of education and its future. Boston: Houghton-Mifflin.

Shu, D. F. (2005). China needs foreign llanguage teaching theories with Chinese characteristics. Foreign Language World, 6, 2-7.

Slavin, R. E. (2003). Educational psychology: Theory into practice (7th ed.). Boston: Allyn \& Bacon.

Wang, G. \& Zhao, H. (2005). On developing study motivation in English language teaching. Sino-US English Teaching, 2(4, Serial 16).

Wang, J. (2008). Stimulating students' motivation in foreign language teaching. US-China Foreign Language, 6(1, Serial 52).

Weinstein, C. S.(1989). Teacher education students' perception of teaching. Journal of Teacher Education, 40(2), 53-60.

Williams, M. \& Burden, R. L. (2000). Psychology for language teachers. Foreign Language Teaching and Research Press.

Wlodkowski, R. J. (1997.) Motivation with a mission: Understanding motivation and culture in workshop design. New Directions for Adult and Continuing Education, 76.

Woolfolk, A. (2004). Educational psychology (9th ed.). Boston: Allyn \& Bacon.

Xu Zhe. (1997). Communicative language teaching. ELI teaching: A journal of theory and practice, 2126.

Zhang R. \& Liang, F. (2008). Survey of college non-english adult learners' english learning motivation and its implications. US-China Foreign Language, 6(3, Serial 54). 